\title{
LA PARTICIPACIÓN DE LOS TRABAJADORES EN LA TECNOLOGÍA El caso de la industria auxiliar del automóvil en Cataluña*
}

\begin{abstract}
JOAQUIN JUAN ALBALATE
Universidad de Barcelona

PALABRAS CLAVE ADICIONALES

Democracia industrial, Control de la tecnología, Empresas privadas.

\author{
ADDITIONAL KEYWORDS \\ Industrial Democracy, Control of Technology,
} Private Companies.

RESUMEN. La participación de los trabajadores en la gestión de la tecnología es un fenómeno sociolaboral poco desarrollado. El análisis del sector auxiliar del automóvil en Cataluña ha permitido constatar que los niveles de participación de los trabajadores y/o sus representantes en el proceso de innovación tecnológica son muy limitados. En este artículo se presentan los resultados más relevantes de la citada investigación, mostrando, mediante estudios de casos, la importancia de las concepciones ideológico-culturales tanto de los directivos de las empresas como de los trabajadores y sus representantes, a la hora de explicar los bajos niveles de participación de éstos en la gestión de la tecnología. A partir de la información recogida, y de acuerdo con el carácter exploratorio de la investigación, el autor propone una tipología de empresas en función del modo diferente con el que tratan este asunto.
\end{abstract}

ABSTRACT. The participation of workers in the managing of technological innovation process is not a common phenomenon in developed countries. The empirical analysis of the Catalonian industry of automotive components confirms that the levels of participation of workers in this process are very low. In this article, the results of such a research are presented, showing the importance of the ideological and cultural conceptions of managers, as well as workers, as explaining factors. In base of the empirical information accumulated through the exploratory research, the author proposes a typology of firms according to how they deal the problem of the participation of workers in the technological innovation process.

\footnotetext{
* Los resultados proceden del análisis efectuado en la primera parte de la tesis doctoral "La participación de los trabajadores en la tecnología. Un enfoque sociocultural de la participación en empresas del sector auxiliar del automóvil de Cataluña", leída en la Universidad de Barcelona, en enero de 2003.

E-mail: jjuana@ub.edu
}

Revista Internacional de Sociología (RIS)

Tercera Época, No 37, Enero-Abril, 2004, pp. 47-76. 


\section{INTRODUCCIÓN}

La colaboración de los trabajadores para incorporar nuevas tecnologías en el proceso de producción se remonta al mismo momento de la aparición de la fabricación mecanizada. Durante las primeras décadas de la revolución industrial, la obtención de los productos se asentaba en la existencia de unas relaciones de cooperación entre los empresarios pre-tayloristas y los trabajadores industriales (Cornfield, 1995: 28). Este tipo de colaboración se debía a la necesidad de los empresarios de mantener las relaciones sociolaborales fundamentadas en el respeto y la confianza mutua con los trabajadores, en la medida que éstos eran los que poseían las cualificaciones y la experiencia profesional para desarrollar los procesos de trabajo adecuadamente.

En un contexto de dependencia mutua como ése, los empresarios sabían que si querían introducir nueva maquinaria era esencial contar con el consentimiento tácito o explícito de los obreros, pues eran éstos los que mejor conocían las características del funcionamiento de las herramientas, máquinas e instalaciones. Además, la existencia de ese espíritu de reciprocidad y colaboración más o menos informal, permitía que los problemas técnicos y averías que se presentaban durante el proceso de producción se pudieran resolver con mayor rapidez y menor coste, gracias al ahorro en mantenimiento que asumían los propios trabajadores.

Es cierto que la existencia de ese espíritu de cooperación no garantizaba la ausencia de conflictos laborales, pero su existencia actuaba de reductor de tensiones en las relaciones sociales de producción, dado que la dependencia técnica comportaba, a su vez, cierta dependencia social entre ambas partes, por más que el control último de dichas relaciones quedasen en manos de los empresarios.

De hecho, este tipo de interdependencia en la gestión de la tecnología y el trabajo fue una de las causas que llevaron a F. W. Taylor a proponer un nuevo concepto de la organización del trabajo. La Organización Científica del Trabajo tenía, entre otros objetivos, la misión de erradicar las formas "arcaicas" de dirigir las empresas y sustituirlas por un nuevo management cientifico, libre de ataduras para así ejercer el control absoluto de la organización del trabajo y de la tecnología y eliminar cualquier tipo de dependencia de las cualificaciones de los trabajadores.

Será pues, a partir de Taylor, que la participación de los trabajadores en la empresa y, particularmente, en el control de la tecnología, iniciará una nueva etapa histórica. Desde entonces, la participación en la tecnología se convertirá en una de las demandas más emblemáticas del movimiento obrero, a pesar de que, por motivos de orden económico, político, bélico o sociolaboral, sufrirá numerosas oscilaciones en cuanto a figurar como meta preferente del calendario reivindicativo sindical.

No obstante, desde finales de los años setenta, parece que esa meta ha pasado a segundo plano para una parte importante de los sindicatos europeos, de tal manera 
que las propuestas y programas de participación relacionados con la gestión de la tecnología han dejado paso a otras reivindicaciones, aparentemente más urgentes y menos aplazables que ésta.

Tal es el estancamiento y, a menudo, la regresión en esta materia, que algunas de las experiencias que parecían haber despertado un mayor grado de expectativas hacia finales de la era fordista o, incluso, después de ella - como, por ejemplo, la que simbólicamente representó la denominada producción "reflexiva", ensayada en la planta de Volvo de Uddevalla (Freyssenet, 1995: 365-366) - hoy se encuentran en plena controversia o, simplemente, han desaparecido como objeto de interés del imaginario dominante en el mundo intelectual y en el propio movimiento sindical.

\section{LA PARTICIPACIÓN TECNOLÓGICA EN ESPAÑA}

Paralelamente se ha podido comprobar que el mayor potencial participativo que ofrecen las actuales tecnologías de producción flexible —en comparación con lo que sucedía con las anteriores tecnologías convencionales- no ha sido suficientemente explotado. La fuente de oportunidades de participación abierta por esta nueva generación de tecnologías (Bamber, 1993: 254) ha sido escasamente aprovechada por los trabajadores a la hora de decidir y definir, junto con los empresarios, la configuración del tipo de funciones y aplicaciones que esas tecnologías habrían de realizar.

De hecho, algunos de los pocos estudios empiricos llevados a cabo a finales de la década de los ochenta y principios de los noventa en el territorio español sobre la participación en la tecnología — por ejemplo, Larrea (1994: 145), Fröhlich et al., (1991: 14) - , ya apuntaban la debilidad de ese tipo de participación.

Y es que, más allá de la dificultad de los sindicatos para prever las consecuencias del intenso despliegue tecnológico que se ha llevado a cabo en el ámbito productivo durante las dos últimas décadas, la decisión de negociar la participación en la gestión de la tecnología ha adquirido y sigue adquiriendo - tanto para estos últimos, como para los directivos- unas connotaciones específicas, con un alcance distinto al que se suele obtener cuando la participación implica a otros ámbitos menos comprometidos para las empresas.

Para explicar este recelo conviene señalar que si los trabajadores o sus representantes accedieran a participar en las decisiones que conciernen a las inversiones de capital — como es el caso de la tecnología - es porque, previamente, se habría llegado a un acuerdo, más o menos formalizado entre ambas partes, de cuya aplicación pudiera derivarse importantes repercusiones en la distribución del poder dentro de las empresas, probablemente superiores a las que se podrían obtener de la participación en la organización de los procesos de trabajo no ligados directamente a la tecnología, o en otros ámbitos que los directivos empresariales 
consideran como menos estratégicos.

En este sentido, y centrándonos en el caso del empresariado de Cataluña, parece que para un número aún bastante elevado de directivos y empresarios (y no sólo catalanes), compartir con la parte social el control -aunque sólo sea parcial- de los medios de producción, todavía simboliza el "principio del fin de la empresa". Es por ello que la cooperación activa de los trabajadores en la toma de decisiones relacionadas con el cambio tecnológico sigue suscitando una gran reacción ideológica entre los primeros, tal como se ha podido comprobar con esta investigación.

Tal es la preeminencia del componente "ideológico-cultural" que, aislado de la influencia de otras variables que podían haber mediado en las decisiones tomadas por los directivos, ese componente ha sido capaz de explicar la mayor parte de los niveles de participación en la tecnología que alcanzaron los trabajadores y sus representantes sindicales en las empresas que se estudiaron en el marco de nuestro estudio.

Ahora bien, que el temor a la pérdida de poder de los directivos haya demostrado ser un importante elemento explicativo de los citados niveles de participación, ha de matizarse por el papel que desarrollan las concepciones ideológicoculturales de los propios representantes sindicales.

Puede decirse que la participación en la tecnología no sólo se ha convertido en un desafío para los directivos empresariales, sino que también lo es para los propios sindicatos. La innovación tecnológica, iniciada ya en algunas empresas españolas a finales de los años setenta, obligó a las organizaciones sindicales a tener que poner al día sus estrategias ante un escenario socioeconómico y político muy distinto al que conocieron antes de desaparecer como tales a finales de los años treinta del siglo precedente como consecuencia de la llegada de la Dictadura franquista.

A diferencia de otros países occidentales, los sindicatos españoles tuvieron que enfrentarse sin dilación y, tras cuarenta años de amnesia sindical, a un cambio tecnológico mucho más veloz, intenso y extenso que los que conocieron durante los tres primeros decenios del siglo XX.

Debe tenerse en cuenta que la superación de ese desfase histórico con el resto de sindicatos europeos, se tuvo que realizar, simultáneamente, con un cambio de régimen político y, en particular, con un entorno económico caracterizado por un elevado desempleo y unas nuevas reglas de competencia dentro de una nueva división internacional del trabajo

No obstante, la actual debilidad de la participación de los trabajadores en general y, específicamente, en la tecnología no puede atribuirse sólo a los anteriores precedentes histórico-políticos, económico-laborales o de orden legal, por importante que haya sido su contribución a esa debilidad, sino que ha de analizarse también - al igual que en el caso de los directivos- por el papel jugado por las concepciones ideológicas que vienen sustentando los representantes sindicales con relación a ese tipo de participación. 
Ambos aspectos - la participación de los trabajadores en la gestión de la tecnología, y la responsabilidad de las concepciones ideológico-culturales de directivos y representantes sindicales sobre esa situación- han constituido el núcleo orientador de esta investigación.

\section{PRESUPUESTOS METODOLÓGICOS DE LA INVESTIGACIÓN}

Con relación a los presupuestos metodológicos de la investigación, se dividieron en dos partes: por un lado, se estableció el diseño que iba a seguir la investigación, y por otro, la metodología propiamente dicha.

Por lo que se refiere al diseño de la investigación, se inició con la delimitación de los significados concretos de los indicadores que habían de representar a las variables de la investigación. Concretamente, para representar al objeto de estudio que se quería indagar en una primera etapa de la investigación, es decir, para detectar los niveles de participación que habían alcanzado los trabajadores o sus representantes en el proceso de innovación tecnológica, se definió la variable "participación de los representantes en la principal tecnología" (PIT), el contenido de la cual quedó delimitado como el grado y extensión de la participación con la que los representantes de los trabajadores - comité de empresa o delegados de personal y, en caso de ausencia de esa representación, los propios trabajadores ${ }^{1}$ - habían participado en alguna o en todas las fases de que se compone el

\footnotetext{
${ }^{1}$ A pesar de que la participación en la innovación tecnológica puede ser directa en el propio puesto de trabajo por parte de cada trabajador o grupo de trabajo, e indirecta, a través de los representantes sindicales, se decidió unir en un único sujeto social -el denominado a partir de ahora "representantes"- a ambas formas potenciales de protagonizar la participación en la tecnología, a fin de facilitar la recogida y clasificación de la información. En este sentido, no siempre es fácil deslindar la frontera entre la participación directa y la indirecta, entre otras razones porque ambos tipos de participación se pueden dar en la práctica de forma solapada, dificultando así su distinción. Por ejemplo, es posible intuir que si existe participación en la fase en que se decide comprar la tecnología, lo sea con los representantes de los trabajadores y no con cada uno de los trabajadores de la empresa. En cambio, durante la fase de implantación de la tecnología, la participación podría darse mediante propuestas directas de mejoras, tanto individualmente, como en grupos de trabajo, aunque esas propuestas podrían provenir o ser canalizadas también a través de los representantes sindicales. Por otro lado, optar por entrevistar a los representantes sindicales cuando éstos existían y no a los trabajadores individualmente, no implicaba, necesariamente, desconocer la participación directa que pudiera haber en la empresa, puesto que los representantes sindicales, además de ejercer la representación de, entre otras cosas, la voluntad participativa de los trabajadores, son, a su vez, trabajadores individuales que, igualmente, pueden participar directamente como tales y, con ello, buenos informantes del alcance que adquiere este tipo específico de participación en su empresa. En todo caso, en las empresas donde no existía representación sindical, el sujeto social "representantes" encarnaba a la participación que, directamente, llevaban a cabo los propios trabajadores.
} 
R I S

proceso de innovación de la "principal tecnología" incorporada por las empresas a estudiar durante los últimos tres años. En nuestro estudio se ha entendido por "principal tecnología" a la tecnología que, entre todas las que se habían podido introducir en el ámbito de la producción durante los últimos tres años, había sido considerada por la empresa como la más importante; y por "grado de participación en la innovación tecnológica" al nivel de intensidad con el que, de menos a más, los "representantes" habían participado en la principal tecnología (ausencia/información unilateral, consulta unidireccional, consulta bidireccional o co-decisión).

Los términos de la escala de participación se han definido del siguiente modo:

- "Ausencia/Información Unilateral": ausencia absoluta de participación o, como mucho, a la existencia de comunicación unilateral de la empresa a los "representantes", sin más derecho de participación que el conocimiento de la decisión tomada por aquélla de introducir la "principal" tecnología;

- "Consulta unidireccional": la participación de los "representantes" para poder realizar, caso de ser consultados, propuestas a la empresa sobre la introducción de la principal tecnología, sin que por ello exista compromiso alguno de la empresa de aceptar tales propuestas.

- "Consulta bidireccional": la participación de los "representantes" para poder ofrecer, de forma negociada, propuestas a la empresa sobre la introducción de la principal tecnología, a pesar de que sólo esta última posea la potestad para tomar la última e irrevocable decisión.

- "Co-decisión": la participación de los "representantes" para poder tomar, conjuntamente con la dirección de la empresa, las principales decisiones relacionadas con la introducción de la principal tecnología, en términos de equidad, en tanto que ambas partes poseen el derecho de veto sobre tales decisiones ${ }^{2}$.

- "Extensión de la participación", a la participación en las distintas fases que, presumiblemente, había tenido que seguir el proceso de innovación de la principal tecnología3: decisión (planificación de la compra de la "principal" tecnología),

\footnotetext{
${ }^{2}$ Se establece el máximo grado de participación que pueden alcanzar los "representantes" en términos de "Co-decisión" y no de "Autogestión", porque el análisis de los casos de empresa que estudiaba esta investigación se centró en organizaciones económicas capitalistas - sociedades anónimas o limitadas - ajenas a la denominada "economía social", como cooperativas de trabajo asociado, sociedades anónimas laborales, etc., en las que la autogestión es, en principio, connatural al "espiritu" de este tipo de organizaciones, por lo que se partió del criterio de que, a priori, no existía ninguna organización empresarial privada en la población a la que pertenecían los casos de empresa a estudiar, en la que los trabajadores pudieran alcanzar el grado de participación en el nivel de autogestión.

${ }^{3}$ Tal como viene definido por los principales organismos internacionales relacionados con esta materia como la OIT (OIT; 1987, 10), la OCDE (OCDE; 1993, 105-125) y, particularmente, por el
} 
diseño (definición o/y selección de las funciones y prestaciones de la "principal" tecnología); implantación (introducción efectiva de la "principal" tecnología en el proceso de producción); y evaluación (valoración de los resultados económicos, técnicos y sociales obtenidos con la "principal" tecnología).

Tras especificar la tipología de grados y extensión potenciales que podían adquirir los niveles de participación de los representantes en la principal tecnología" (PIT), en los casos a estudiar quedó definido el caso de empresa óptimo de la investigación: aquella que cumpliera los máximos participativos previstos, es decir, donde el Grado (\&) con el que habían participado los representantes en la innovación de la principal tecnología fuera en términos de Co-decisión y que alcanzara a todas las fases $(\mathrm{k})$ de que consta ese proceso.

En otras palabras, PIT era una función de $\&, k$ : donde $\&$ podía tomar las categorías: Ausencia/Información Unilateral; Consulta unidireccional, Consulta bidireccional y Co-decisión; y donde $k$, podía tomar las categorías: Ninguna; Implantación; Diseño, Evaluación o Todas, incluyendo en este caso a la fase de Decisión.

Una vez descrito, sintéticamente, el diseño de la investigación, se pasó a detallar la metodología utilizada por la investigación. Concretamente, se recurrió a los estudios de caso. A pesar de que esta técnica de investigación no permite extrapolar los resultados del análisis de un determinado fenómeno social a toda la población a la que pertenecen el caso o los casos elegidos, se optó por esta técnica cualitativa porque era la que mejor se adaptaba al principal objetivo de la investigación: conocer y aprehender, con el grado de profundidad necesario, los razonamientos y motivaciones - a veces complejos y de difícil captura con técnicas cuantitativas - con los que los dos sujetos sociales justificaban sus discursos sobre la pertinencia o la importancia, respectivamente, de la participación en el proceso de innovación tecnológica llevado a cabo en el seno de las empresas.

Este tipo específico de información suele permanecer oculta y retenida en la mente de los individuos cuando son requeridos para responder a una encuesta. Es en ese sentido que los estudios de caso se convierten en una opción apropiada para alcanzar la información que se desea, a pesar de las citadas limitaciones.

Además, a todo ello se sumaba el hecho de que la idea de llevar a cabo un procedimiento de análisis cuantitativo utilizando una muestra aleatoria, quedaba prácticamente descartado. Y eso era así porque la dimensión de la población de empresas en la que se iba a estudiar el fenómeno participativo, era lo suficientemente pequeña (237 empresas), como para que esa vía resultara una alternativa factible.

programa de investigación "Participación Directa en el Cambio Organizacional" (EPOC, 1996), de la Fundación Europea para la Mejora de las Condiciones de Vida y Trabajo, de la Unión Europea. Ver también (Fröhlich et al, 1990: 4). 
R I S

REVISTA INTERNACIONAL DE SOCIOLOCIA

No 37, ENER0-ABRIL, 2004

JOAQUÍN JUAN ALBALATE

Tras optar, pues, por los estudios de caso, se pasó a planificar el proceso de obtención de la información. Éste se inició con la selección de un conjunto de empresas de un listado alfabético proporcionado por la principal patronal del sector. $Y$ aunque no se trataba de elaborar una muestra aleatoria, como ya se ha indicado, se quiso forzar que los casos a seleccionar cumplieran con los siguientes criterios de proporcionalidad, a fin de aproximarse a un cierto grado de representatividad:

- Que el número de casos seleccionados en cada una de las poblaciones de empresas de los dos subsectores auxiliares elegidos ("producción de piezas y componentes metálicos" y "producción e inyección de plástico y caucho"), se aproximara en lo posible al peso relativo de las dos poblaciones de esos dos subsectores ${ }^{4}$.

- Que esa misma proporcionalidad se guardara, simultáneamente, con la distribución por segmentos de tamaño existente en las dos poblaciones citadas, en términos de: menos de 50 trabajadores, entre 50 y 250 trabajadores, y más de 250 trabajadores.

- Que todos los casos elegidos lo fueran también de municipios con una elevada densidad de empresas de esos dos subsectores, sin que pudiera haber más de un caso de empresa de un mismo municipio.

Pues bien, como consecuencia de la aplicación de esos criterios, quedaron seleccionados, finalmente, quince casos de empresa del citado listado. No obstante, aparecieron ciertos problemas a la hora de completar esos casos.

Previendo el surgimiento de alguno de esos problemas (como por ejemplo el rechazo al acceso a la información en alguna de las empresas previamente seleccionadas), se decidió llevar a cabo una estrategia sistemática de persuasión dirigida a los principales responsables de esas empresas. Para empezar, antes de contactar con las empresas, se realizó el envío anticipado de una carta en la que se explicaban los pormenores de la investigación, haciendo hincapié en el interés que podía conllevar, para ambas partes, la colaboración de la empresa en la investigación.

Los resultados del citado envío fueron relativamente exitosos, pues permitió con uno o varios contactos telefónicos posteriores, confirmar con bastante facilidad a diez de las quince empresas seleccionadas en una primera instancia. Con el resto de las empresas, la labor de apertura fue más compleja, hasta el punto de que dos de los cinco casos anteriores, tuvieron que ser substituidos por otros tantos con características equivalentes, mientras que en los otros tres, dicha apertura se

\footnotetext{
${ }^{4}$ Estos dos subsectores fueron elegidos en razón a la importancia que tienen en la industria auxiliar de Cataluña, tanto por el número de empresas y de trabajadores que congregan, como por el valor añadido y el número, variedad e innovación de productos que se genera en su seno, respecto del conjunto total del sector en esta Comunidad Autónoma.
} 
aplazó en el tiempo y, aunque al final fue posible acceder a la información que se perseguía, hubo que invertir, no sólo tiempo, sino dinero en numerosas llamadas telefónicas y en desplazamientos múltiples por visitas fallidas.

En definitiva, salvo en dos casos, se consiguió que el elenco de empresas finalmente seleccionadas coincidiera, a la postre, con el que se propuso en una primera instancia. Y eso fue importante, no sólo porque así se respetaba en buena medida el principio de concordancia entre empresas seleccionadas a priori y empresas realmente estudiadas, sino porque - como más tarde se pudo comprobar durante el trabajo de campo- los casos elegidos habían sido los necesarios y suficientes para obtener el volumen y, sobre todo, la calidad y variedad de la información, con la profundidad que se había propuesto desde un inicio.

\section{EL TRABAJO DE CAMPO}

Vistos los principales presupuestos metodológicos, el inicio del trabajo de campo consistió, como ya se ha indicado, en detectar los niveles de participación en la tecnología existentes en las quince empresas a estudiar.

$\mathrm{La}$ aplicación del pertinente guión-entrevista para obtener de los informantes de las citadas empresas la cantidad y, especialmente, la calidad de la información considerada necesaria para cubrir los objetivos de la investigación, proporcionó un importante material fruto del proceso sistemático que se siguió para obtener dicha información.

El Cuadro 1 permite tomar un primer contacto con la citada información, mediante la descripción de las que se consideraron principales características generales que identificaban a cada uno de los quince casos de empresas de los que se obtuvo dicha información.

La observación del Cuadro 1 permite comprobar, en primer lugar, cómo se concretaron los tres criterios metodológicos aplicados a la muestra de casos elegida: la variación en la distribución de las empresas entre distintos municipios (uno por municipio) de entre los que tenían una elevada densidad de empresas "auxiliares" en el territorio de Cataluña ( $2^{\mathrm{a}}$ columna); la variación en la distribución del peso relativo de los casos en función del subsector o tipo de producto producido ( $5^{\mathrm{a}}$ columna) y, finalmente, esa misma variación en la distribución de dichos casos por segmentos de tamaño (columna $7^{\mathrm{a}}$ ).

Respecto de la antigüedad de las empresas a estudiar, mientras seis se fundaron a partir de la década de los setenta, las nueve restantes lo habían hecho con antelación a esa década, con unos extremos de antigüedad que oscilaban entre 1916 (Empresa 2) y 1989 (Empresa 6), y una media fundacional situada alrededor de 1960. Con las cautelas necesarias por no constituir una muestra aleatoria, la existencia de una antigüedad media de 40 años, informaba de la presencia de un "tejido" empresarial en el sector "auxiliar" catalán, relativamente envejecido, 
RIS

REVISTA INTERNACIONAL DE SOCIOLOGIA

Cuadro 1.

Datos generales de las empresas estudiadas

\begin{tabular}{|c|c|c|c|c|}
\hline DMPRESAS & 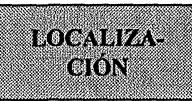 & $\begin{array}{l}\text { ANTIL } \\
\text { GUEDLD } \\
\text { EMPRESA }\end{array}$ & probuctos & SUBSECTOR \\
\hline Empresa 1 & $\begin{array}{l}\text { Sant Vicenç } \\
\text { dels Horts }\end{array}$ & 1951 & $\begin{array}{c}\text { Piezas metálicas } \\
\text { sinterizadas }\end{array}$ & $\begin{array}{l}\text { Producción de piezas y } \\
\text { partes para el automóvil }\end{array}$ \\
\hline Empresa 2 & $\begin{array}{l}\text { Sant Just } \\
\text { Desvern }\end{array}$ & 1916 & $\begin{array}{c}\text { Tubos y perfiles } \\
\text { de caucho }\end{array}$ & $\begin{array}{l}\text { Inyección y producción } \\
\text { de plástico/cuacho }\end{array}$ \\
\hline Empresa 3 & $\begin{array}{l}\text { Sant Adríà } \\
\text { del Besós }\end{array}$ & 1945 & $\begin{array}{l}\text { Bloques mecánicos } \\
\text { metálicos diversos }\end{array}$ & $\begin{array}{c}\text { Producción de piezas y } \\
\text { partes para el } \\
\text { automóvil }\end{array}$ \\
\hline Empresa 4 & $\begin{array}{l}\text { L'Hospitalet } \\
\text { del Llobregat }\end{array}$ & 1971 & $\begin{array}{c}\text { Montaje y reparación } \\
\text { de parabrisas }\end{array}$ & $\begin{array}{c}\text { Producción de piezas y } \\
\text { partes para el } \\
\text { automóvil }\end{array}$ \\
\hline Empresa 5 & $\begin{array}{l}\text { Montones } \\
\text { del Vallès }\end{array}$ & 1973 & $\begin{array}{c}\text { Piezas mecanizadas } \\
\text { para frenos } \\
\end{array}$ & $\begin{array}{l}\text { Producción de piezas y } \\
\text { partes para automóvil }\end{array}$ \\
\hline Empresa 6 & $\begin{array}{l}\text { Sant Andreu } \\
\text { de la Barca }\end{array}$ & 1989 & $\begin{array}{c}\text { Parasoles, rejillas } \\
\text { altavoces, } \\
\text { luces interiores }\end{array}$ & $\begin{array}{l}\text { Inyección y producción } \\
\text { de plástico/cuacho }\end{array}$ \\
\hline Empresa 7 & $\begin{array}{l}\text { Molins } \\
\text { de Rei }\end{array}$ & 1957 & $\begin{array}{l}\text { Centrales de } \\
\text { intermitencia }\end{array}$ & $\begin{array}{c}\text { Inyección y producción } \\
\text { de plástico/cuacho }\end{array}$ \\
\hline Empresa 8 & Fonollosa & 1973 & $\begin{array}{l}\text { Aros de acero para } \\
\text { tubos calefacción }\end{array}$ & $\begin{array}{l}\text { Producción de piezas y } \\
\text { partes para el autom. }\end{array}$ \\
\hline Empresa 9 & $\begin{array}{c}\text { Cornellà } \\
\text { del Llobregat }\end{array}$ & 1974 & $\begin{array}{c}\text { Mecanizado de } \\
\text { piezas para diversos } \\
\text { conjuntos }\end{array}$ & $\begin{array}{c}\text { Produción de piezas y } \\
\text { partes para } \\
\text { el automóvil }\end{array}$ \\
\hline Empresa 10 & Badalona & 1971 & $\begin{array}{l}\text { Adaptación mecánica } \\
\text { robots soldadura }\end{array}$ & $\begin{array}{c}\text { Producción de piezas y } \\
\text { partes para } \\
\text { el automóvil }\end{array}$ \\
\hline Empresa 11 & Martorell & 1959 & $\begin{array}{l}\text { Antivibradores } \\
\text { de caucho para } \\
\text { motor y ejes }\end{array}$ & $\begin{array}{c}\text { Inyección y } \\
\text { producción de plástico/ } \\
\text { cuacho }\end{array}$ \\
\hline Empresa 12 & $\begin{array}{c}\text { El Prat } \\
\text { del Llobregat }\end{array}$ & 1953 & $\begin{array}{l}\text { Fundas y mandos } \\
\text { de cables }\end{array}$ & $\begin{array}{c}\text { Producción de piezas } \\
\text { y partes para } \\
\text { el automóvil }\end{array}$ \\
\hline Empresa 13 & Les Franqueses & 1961 & $\begin{array}{l}\text { Amortiguadores } \\
\text { y suspensiones }\end{array}$ & $\begin{array}{l}\text { Producción de piezas y } \\
\text { partes para el automóvil }\end{array}$ \\
\hline Empresa 14 & Ripollet & 1958 & $\begin{array}{l}\text { Fundas y mandos } \\
\text { de cables }\end{array}$ & $\begin{array}{c}\text { Producción de piezas y } \\
\text { partes para } \\
\text { el automóvil }\end{array}$ \\
\hline Empresa 15 & Barcelona & 1955 & $\begin{array}{c}\text { Ejes para la caja } \\
\text { de cambios }\end{array}$ & $\begin{array}{c}\text { Producción de piezas y } \\
\text { partes para } \\
\text { el automóvil }\end{array}$ \\
\hline
\end{tabular}

Fuente: Elaboración propia 
Cuadro 1

Datos generales de las empresas estudiadas

\begin{tabular}{|c|c|c|c|c|}
\hline $\begin{array}{l}\% \\
\text { EXPORTA- } \\
\text { CIONES }\end{array}$ & $\begin{array}{l}\text { Tamiaño } \\
\text { (trabajadores) }\end{array}$ & \% MUIERES & $\begin{array}{l}\text { "PRINCIPAL" } \\
\text { INNOVACIÓN } \\
\text { TECNOLOGICA }\end{array}$ & $\begin{array}{l}\text { REPRESENTACIÓN } \\
\text { SINDICAL }\end{array}$ \\
\hline $80 \%$ & 300 & $15 \%$ & Hornos de sinterizado & $\begin{array}{l}\text { UGT } 8, \mathrm{CCOO} 4 \text {, } \\
\text { Independientes } 1\end{array}$ \\
\hline $63 \%$ & 220 & $8 \%$ & Máquinas de estrusión & CCOO 5, UGT 4 \\
\hline $40 \%$ & 38 & $12 \%$ & CNC's & $\begin{array}{c}\text { La representación } \\
\text { sindical la ejercen } \\
\text { personas de la empresa }\end{array}$ \\
\hline $0 \%$ & 15 & $8 \%$ & $\begin{array}{l}\text { Utillaje y equipos de } \\
\text { presión fijadores }\end{array}$ & $\begin{array}{l}\text { No hay } \\
\text { representación } \\
\text { sindical }\end{array}$ \\
\hline $5 \%$ & 19 & $18 \%$ & CNC's & $\begin{array}{c}\text { No hay representación } \\
\text { sindical }\end{array}$ \\
\hline $80 \%$ & 280 & $95 \%$ & PLC's & UGT 11, 2 USO \\
\hline $60 \%$ & 26 & $80 \%$ & $\begin{array}{c}\text { Automatización línea } \\
\text { de montaje }\end{array}$ & Independiente 1 \\
\hline $0 \%$ & 24 & $3 \%$ & Robot soldadura & $\begin{array}{c}\text { No hay representación } \\
\text { Sindical }\end{array}$ \\
\hline $50 \%$ & 60 & $5 \%$ & CNC's & $\mathrm{CCOO} 5$ \\
\hline $5 \%$ & 154 & $20 \%$ & $\begin{array}{l}\text { Instrumental de } \\
\text { medición láser }\end{array}$ & UGT 9 \\
\hline $60 \%$ & 180 & $15 \%$ & $\begin{array}{c}\text { Prensas de inyección } \\
\text { de caucho }\end{array}$ & $\mathrm{CCOO} 9$ \\
\hline $12 \%$ & 83 & $5 \%$ & $\begin{array}{l}\text { Máquinas cableadoras } \\
\text { y prefiladoras }\end{array}$ & $\begin{array}{c}\text { La representación } \\
\text { sindical la ejercen } \\
\text { personas de la empresa }\end{array}$ \\
\hline $18 \%$ & 28 & $10 \%$ & Robot para montaje & Independiente 1 \\
\hline $80 \%$ & 486 & $20 \%$ & $\begin{array}{l}\text { Máquinas de } \\
\text { inyección de plástico }\end{array}$ & $\begin{array}{c}\text { UGT 7, COP } 6 \\
\text { (Candidatura escisión } \\
\text { de CCOO) }\end{array}$ \\
\hline $6 \%$ & 51 & $4 \%$ & CNC's & CCOO 4, UGT 1 \\
\hline
\end{tabular}

Fuente: Elaboración propia 
siendo el flujo de entrada de nuevas empresas insuficiente para compensar la elevada antigüedad de las que se crearon a partir de las décadas de los cuarenta y cincuenta.

Por su parte, observando el tipo de productos (cuarta columna), se puede apreciar que, entre los diversos que podían existir en cada empresa, el que figura en esa columna era el considerado por la propia empresa como el más importante por el volumen de facturación que reportaba. La variedad de los productos era la tónica general y, sólo en el caso de las empresas 12 y 14, ese dato era coincidente.

El porcentaje de exportación sobre el total de la producción (columna seis), permitió conocer el grado de internacionalización de cada empresa. Mientras tres de las seis empresas de tamaño mediano (de 50 a 249 trabajadores) y, particularmente, todas las de gran tamaño (de 250 o más trabajadores), concentraban las tasas de exportación más elevadas, era entre el resto de empresas donde se encontraban las tasas menores, aunque con una gran variación entre ellas. Mientras una pequeña empresa, como la 7 , exportaba en un $60 \%$, otra de tamaño medio (como la empresa 10) sólo lo hacía en un $5 \%$, mientras que otras, igualmente de pequeña dimensión (como las empresas 4 y 8 ), presentaban un porcentaje de exportaciones nulo.

Por lo que respecta a la presencia femenina en las quince empresas estudiadas (octava columna), se puede comprobar que tal presencia sólo superaba el $20 \%$ en dos de ellas, en clara concordancia con el peso relativo que alcanzaba la ocupación de la mujer en el sector industrial y, en particular, en el del metal. La elevada sobrerepresentación femenina detectada en las empresas 6 y 7 fue justificada por ambas direcciones, aunque por motivos muy distintos. Mientras en el primer caso esa opción respondía a un criterio de mayor productividad que los varones en el trabajo en cadena, en el segundo respondía a la preferencia por las actitudes más responsables y cooperadoras de las mujeres, según ese interlocutor, para con las propuestas de gestión co-participada iniciadas a instancia de esta empresa.

Sobre la elección que cada empresa efectuó sobre la que consideraba como principal innovación tecnológica de entre todas las que se habían introducido durante los últimos tres años, tal elección dio lugar a un amplio espectro de innovaciones (novena columna), siendo la gran mayoría específicas de los dos subsectores auxiliares en la transformación metálica y del caucho-plástico, aunque con una presencia destacada de tecnologías "transversales" a otros sectores industriales, como el Control Numérico Computerizado (CNC) o de robots, en especial, en el primero de esos subsectores.

Por último, la décima columna muestra la gran diversidad de situaciones con las que se configuraba la representación sindical de las quince empresas estudiadas. Esas situaciones se caracterizaban por la propia inexistencia de tal representación en tres de estas empresas (empresas 4, 5 y 8 ) y por la representación sindical ejercida por personal de la propia empresa (empresas 3 y 12), 
catalogada por esta investigación como de nula representatividad, al entender que se trataba de una suplantación irregular de los trabajadores.

Respecto de las empresas con representación sindical real, eran CCOO y UGT - en diversas proporciones - las que prevalecían, a veces junto a otras candidaturas, a veces en solitario. Finalmente, sólo en dos de las diez empresas con representación sindical —ambas de pequeña dimensión (empresas 7 y 13) - el delegado sindical elegido era de una candidatura independiente.

\section{LOS RESULTADOS DE LA PARTICIPACIÓN EN LA TECNOLOGÍA}

Vistas las principales características de las quince empresas seleccionadas, la clasificación de la información que se obtuvo de estas empresas se llevó a cabo mediante la aplicación de un indicador que recogía los criterios metodológicos apuntados en el anterior epígrafe 2, atendiendo, aunque con mayor detalle, al esquema utilizado por el programa de investigación EPOC, de la Fundación Europea para la Mejora de las Condiciones de Vida y Trabajo (1996), de la Unión Europea, para analizar las políticas de participación en Europa. Esta clasificación quedó concretada según el cuadro 2.

La aplicación del anterior instrumento clasificatorio a la información recabada de las quince empresas proporcionó los siguientes niveles de participación (grado y extensión) que se recogen en el cuadro 3.

La recapitulación de la información contenida en el cuadro 3 permitió comprobar que la situación de la participación en la tecnología se había distribuido de la siguiente forma:

- En seis de las quince empresas estudiadas (empresas 5, 6, 8, 9, 13 y 15), no se pudo detectar participación alguna, ni en grado ni en extensión.

- En tres de las nueve empresas restantes (empresas 1, 11 y 12), se registró una extensión de la participación mínima en la fase de Implantación, pero con un grado de Información Unilateral.

- En otras tres (empresas 3, 4 y 10), se registró la misma extensión de la participación, aunque con un grado de Consulta Unidireccional previa a los trabajadores o representantes sindicales.

- Por último, mientras que en otras dos empresas (Empresas 2 y 14) se alcanzó una participación con un grado de Consulta Bidireccional, con una extensión que alcanzó a la fase de Diseño de la tecnología; tan sólo en una empresa (Empresa 7), se pudo detectar una participación con el grado de Co-decisión, aunque limitado al volumen de la inversión, con una extensión igualmente máxima, es decir, que abarcaba a todas las fases del proceso de innovación tecnológica.

La traslación de toda la anterior información a un nuevo cuadro de doble entrada, permitió reobservar dicha información de la siguiente forma resumida: 


\section{RIS}

Cuadro 2

Tipos de participación de los "representantes"en la principal tecnología.

\begin{tabular}{|c|c|}
\hline $\begin{array}{c}\text { GRADO CON QUE SE PARTICIPA } \\
\text { (Intensidad o grado de la participación en el } \\
\text { proceso de innovación) }\end{array}$ & $\begin{array}{c}\text { CÓMO Y DÓNDE SE PARTICIPA } \\
\text { (Extensión of formas de la participación en las } \\
\text { diversas fases del proceso de innovación) }\end{array}$ \\
\hline $\begin{array}{c}\text { (1) Ausencia o Información unilateral } \\
\text { (Aus/Inf) }\end{array}$ & $\begin{array}{c}\text { (A) Ausencia de formas } \\
\text { de participación en fase alguna } \\
\text { (Part/Nula) }\end{array}$ \\
\hline $\begin{array}{c}\text { (2) Consulta unidireccional } \\
\text { (Cons/Unid) }\end{array}$ & $\begin{array}{c}\text { (B) Propuestas de mejora a posterióri, en la } \\
\text { fase de Implantación o/y en la de Evaluación } \\
\text { (Part/Minima) }\end{array}$ \\
\hline $\begin{array}{c}\text { (3) Consulta bidireccional } \\
\text { (Cons/Bid) }\end{array}$ & $\begin{array}{c}\text { (C) Propuestas a priori en la fase de Diseñó y } \\
\text { de mejora a posteriori } \\
\text { en Implantación o/y Evaluación } \\
\text { (Part/Media) }\end{array}$ \\
\hline $\begin{array}{c}\text { (4) Co-decisión } \\
\text { (Co-deci) }\end{array}$ & $\begin{array}{c}\text { (D) Propuestas a priori en las fases } \\
\text { de Decisión y Diseño y de mejora a posteriori } \\
\text { en las de Implantación y Evaluación } \\
\text { (Part/Máxima) }\end{array}$ \\
\hline
\end{tabular}

Fuente: Elaboración propia, a partir de EPOC, 1996.Siendo:

(1) Ausencia absoluta de Información o existencia de Información unilateral de la empresa sin derecho a réplica alguna

(2) Consulta de la empresa a "representantes", pero sin compromiso de la empresa a aceptar las propuestas de éstos

(3) Consulta de la empresa negociada con los "representantes", pero la decisión última es siempre de la empresa

(4) Decisión conjunta consensuada, con derecho de veto de ambas partes.

A la vez que:

(A) Nula participación en fase alguna

(B) Propuestas de mejora tras la Implantación de la "principal" tecnología (en el presente) o/y en la fase de Evaluación (de cara al futuro)

(C) Propuestas de mejora previas en la fase de Diseño (anticipación parcial), y a posteriori, en Implantación (presente) o/y Evaluación (futuro)

(D) Propuestas de mejora previas en las fases de Decisión y Diseño (anticipación íntegra), y a posteriori en las de Implantación (presente) o/y Evaluación (futuro). 
Cuadro 3

Grado y fases de la participación de los "representantes" en la principal tecnología, en las empresas estudiadas

\begin{tabular}{|c|c|c|c|}
\hline EMPRESAS & $\begin{array}{l}\text { QRAIO } \\
\text { DELA } \\
\text { PARTICI- } \\
\text { PACION }\end{array}$ & $\begin{array}{l}\text { EXTENSION } \\
\text { DELA } \\
\text { PARTICIPA- } \\
\text { CION }\end{array}$ & COMIENTARIOS \\
\hline EMPRESA 1 & (Aus/Inf) & (Part/Minima) & $\begin{array}{l}\text { Información trimestral previa de la empresa a Comité, } \\
\text { aceptándose algunas propuestas de mejora del Comité/ } \\
\text { trabajadores en fase de Implantación. }\end{array}$ \\
\hline EMPRESA 2 & (Cons/Bid) & (Part/Media) & $\begin{array}{l}\text { Propuestas Comité en fase Diseño, en Comisión pari- } \\
\text { taria con empresa (Consulta negociada), pero limitadas } \\
\text { por derecho empresa a veto, si inversión es elevada. }\end{array}$ \\
\hline EMPRESA 3 & (Cons/Unid) & (Part/Mínima) & $\begin{array}{l}\text { Propuestas de mejora de trabajadores, a nivel de } \\
\text { Consulta sin compromiso de aceptación, en fases de } \\
\text { Implantación y Evaluación. }\end{array}$ \\
\hline EMPRESA 4 & (Cons/Unid) & (Part/Mínima) & $\begin{array}{l}\text { Propuestas de mejora de trabajadores, a nivel de } \\
\text { Consulta sin compromiso de aceptación, en fase de } \\
\text { Implantación. }\end{array}$ \\
\hline EMPRESA 5 & (Aus/Inf) & (Part/Nula) & $\begin{array}{l}\text { No hay Información ni fase donde participe Comité/ } \\
\text { trabajadores. Pura adaptación de los trabajadores a la } \\
\text { tecnología. }\end{array}$ \\
\hline EMPRESA 6 & (Aus/Inf) & (Part/Nula) & $\begin{array}{l}\text { Información mensual previa de la empresa al Comité, } \\
\text { sin opción a propuestas ni participación alguna en } \\
\text { ninguna fase. Pura adaptación de los trabajadores a } \\
\text { la tecnologia. }\end{array}$ \\
\hline EMPRESA 7 & (Co-deci) & (Part/Máxima) & $\begin{array}{l}\text { Participación delegado sindical, a nivel de Codecisión } \\
\text { con dirección en todas las fases, con limitación en la } \\
\text { de Decisión, si inversión es elevada. }\end{array}$ \\
\hline EMPRESA 8 & (Aus/Inf) & (Part/Nula) & $\begin{array}{l}\text { No hay Información ni fase donde participe Comité/ } \\
\text { trabajadores. Pura adaptación de los trabajadores a la } \\
\text { tecnología. }\end{array}$ \\
\hline EMPRESA 9 & (Aus/Inf) & (Part/Nula) & $\begin{array}{l}\text { No hay Información ni fase donde participe Comité/ } \\
\text { trabajadores. Pura adaptación de los trabajadores a la } \\
\text { tecnología. }\end{array}$ \\
\hline EMPRESA 10 & (Cons/Unid) & (Part/Minima) & $\begin{array}{l}\text { Propuestas de mejora de Comité/trabajadores, a nivel } \\
\text { de Consulta sin compromiso de aceptación, en fase } \\
\text { de Implantación. }\end{array}$ \\
\hline EMPRESA 11 & (Aus/Inf) & (Part/Mínima) & $\begin{array}{l}\text { información trimestral previa de la empresa al Comité, } \\
\text { aceptándose algunas propuestas de mejora Comité/ } \\
\text { trabajadores, en fase de Implantada tecnología. }\end{array}$ \\
\hline EMPRESA 12 & (Aus/Inf) & (Part/Mínima) & $\begin{array}{l}\text { No hay Información, aunque se aceptan algunas } \\
\text { propuestas de mejora en Implantación, pero muy } \\
\text { limitadamente. }\end{array}$ \\
\hline EMPRESA 13 & (Aus/Inf) & (Part/Nula) & $\begin{array}{l}\text { No hay Información ni fase donde participe Comité/ } \\
\text { trabajadores. Pura adaptación de los trabajadores a la } \\
\text { tecnología. }\end{array}$ \\
\hline EMPRESA 14 & (Cons/Bid) & (Part/Media) & $\begin{array}{l}\text { Propuestas Comité en fase Diseño, en Comisión pari- } \\
\text { taria con empresa (Consulta negociada), pero limitadas } \\
\text { a las tecnologías construidas internamente. }\end{array}$ \\
\hline EMPRESA 15 & (Aus/Inf) & (Part/Nula) & $\begin{array}{l}\text { No hay Información ni fase donde participe Comité/ } \\
\text { trabajadores. Pura adaptación de los trabajadores a la } \\
\text { tecnologia. }\end{array}$ \\
\hline
\end{tabular}

Fuente: Elaboración propia. 


\section{Cuadro 4.}

Distribución de las empresas estudiadas, según el grado y las fases de la participación en la "principal" tecnología.

\begin{tabular}{|c|c|c|c|c|}
\hline $\begin{array}{l}\text { Fases } \\
\text { Grado } \\
\text { (Intensidad) }\end{array}$ & $\begin{array}{l}\text { Ausencia de } \\
\text { participación en } \\
\text { fase alguna }\end{array}$ & $\begin{array}{l}\text { Participación en } \\
\text { fases Implanta- } \\
\text { ción/ Evaluación }\end{array}$ & $\begin{array}{l}\text { Participacion en } \\
\text { fases Diseño } \\
\text { Implantación/ } \\
\text { Evaluación }\end{array}$ & $\begin{array}{l}\text { Participación en } \\
\text { todas las fases }\end{array}$ \\
\hline $\begin{array}{l}\text { Ausencia-Inform. } \\
\text { Unilateral }\end{array}$ & $\begin{array}{c}\text { Empresas } \\
5,6,8,9,13,15\end{array}$ & $\begin{array}{c}\text { Empresas } \\
1,11,12\end{array}$ & & \\
\hline $\begin{array}{l}\text { Consulta } \\
\text { Unidireccional }\end{array}$ & & $\begin{array}{c}\text { Empresas } \\
3,4,10\end{array}$ & & 8 \\
\hline $\begin{array}{l}\text { Consulta } \\
\text { Bidireccional }\end{array}$ & & & $\begin{array}{c}\text { Empresas } \\
2,14\end{array}$ & \\
\hline Codecisión & & & & $\begin{array}{c}\text { Empresa } \\
7\end{array}$ \\
\hline
\end{tabular}

Fuente: Elaboración propia.

Ante los resultados alcanzados en la participación en la principal tecnología que muestra el anterior Cuadro 4, los directivos de las quince empresas intentaron justificar tales resultados interponiendo una serie de discursos justificativos que ilustraban, en general, un elevado grado de coherencia con los respectivos niveles de participación que, efectivamente, se alcanzaron.

Así, entre los directivos de las empresas en las que el grado de la participación había sido nulo, los comentarios registrados se dividieron en dos bloques. Por un lado, los relativos a aquellas empresas en las que, no sólo el grado, sino también la extensión de la participación, había sido inexistente. En este caso, las expresiones que se transcribieron fueron, entre otras, las siguientes:

“...Eso de participar queda muy bien...ya lo he oído de alguno en alguna reunión [de la asociación patronal local]...pero nosotros aunque quisiéramos no podemos...tenemos muchos follones que resolver cada día... sólo nos faltaría montar el trabajo con grupos..." (Empresa 5)

“...Es a los MI y a los de dirección a los que les hemos pedido una opinión previa sobre las características que habían de tener los nuevos PLC's...Aunque esa opinión no fue definitiva porque siempre recurrimos al Departamento de Ingeniería antes porque es el que decide definitivamente sobre este tema...Bueno, en realidad, no nos 
hemos planteado nunca que el Comité tenga que inmiscuirse en esto...No creo que le toque..." (Empresa 6).

“...La función del operario es trabajar...¿dónde has visto tu una empresa donde los empleados van a discutir de cosas que no les pertenecen...?" (Empresa 8)

“...Mira, tal como están todas las cosas, cualquier empresario busca no ampliar las plantillas y disminuirlas... las máquinas no se ponen enfermas, ni cogen bajas, ni agarran la gripe,...las máquinas no han de adaptarse a los trabajadores, sino que son los trabajadores los que han de adaptarse a cualquier cambio que haya...yo lo veo así... Y en el sector que estamos, cuantos menos trabajadores tengas, menos costes salariales, mejor..." (Empresa 9).

“...No se les informó ni se les consultó porque, cuando quieres saber algo de finanzas, te vas al banquero, ¿no? Pues esto es lo mismo...Dar esta decisión a personas que vienen aquí a pasar el día, como aquel que dice, es un poco fuerte ¿no?... No tienen ni las capacidades ni el derecho a decir lo que conviene a la empresa...Los sindicatos dan miedo que se metan dentro...El delegado aquí no tiene ningún sentido...Si te entra gente de ésta sólo pretenden ralentizar la faena y si pueden hacer asambleas y perder contra más horas mejor. Esto va contra la pequeña empresa...” (Empresa 13)

“...La empresa no es que no quiera que participen, pero no nos lo hemos planteado...La verdad es que como tampoco nos lo pide el Comité...Ya nos gustaría que se implicasen más, la verdad...Tengo la sensación de que ni les interesa ir más allá de mejoras salariales...[La compra de los $\mathrm{CNC}$ ] es algo que siempre ha de decidir sólo la dirección...No es una cosa de que no estén preparados para tomar estas decisiones, es que hay mucho dinero en juego y... ¿proponer mejoras del equipo? Eso sí que queremos, pero tampoco quieren..." (Empresa 15)

Por su parte, cuando el grado de la participación fue nulo, pero, en cambio, se detectaron prácticas participativas - aunque con carácter de mínimos- a iniciativa de la empresa, y limitadas a propuestas de mejora sobre la principal tecnología, exclusivamente en la fase de Implantación, una vez ya instalada la tecnología, los comentarios aducidos fueron los siguientes:

“...Hasta no hace mucho sólo existía la mera información sobre el cambio que se había decidido sin su colaboración [del Comité]...Ahora, hemos acordado a petición propia del Comité que los trabajadores puedan ofrecer propuestas de mejora sobre las nuevas tecnologías que estamos introduciendo (planchas prensadoras y hornos a gas)...no nos ha parecido mal...todo lo que sea para que mejore la empresa siempre es bueno...” (Empresa 1)

“...Nos gusta que los trabajadores nos digan qué se puede mejorar... Claro que saben más que yo los truquillos de la máquina, por eso hemos establecido canales para que 
hagan propuestas... Yo creo que con esto a algunos les ha subido la moral...y lo entiendo porque tantas horas ahí haciendo lo mismo...Bueno, en realidad si lo que nos proponen cuesta bastante nos lo pensamos dos veces, ya me entiendes..." (Empresa 11)

“...Desde que pusimos la ISO 9000 existe un buzón de sugerencias: muchas veces el trabajador sabe más que el que está en la oficina...Les informamos de que íbamos a comprar las nuevas cableadoras, pero no hacen muchas propuestas, pero estamos en ello...Cuando las implantamos decidimos darles una pequeña prima para alentarlos a que participen, para que se animen a proponer algo que pueda mejorar el puesto con la nueva máquina, pero...Ahora estamos discutiendo la ley de Prevención de Riesgos con dos trabajadores que no son "sindicalistas..." (Empresa 12)

Junto a estas tres últimas empresas, en otras tres se pudo comprobar que, aunque el grado de participación había tenido un rango superior (Consulta unidireccional), el alcance de la extensión en las fases del citado proceso había dado lugar a iguales resultados que en las tres empresas precedentes, con la salvedad de la empresa 3, en la que tal extensión había alcanzado a la fase de Evaluación. Las expresiones que se registraron de los respectivos directivos fueron en este caso las siguientes:

"...Sí que les consultamos por si ven algo que se ha de mejorar. Hemos podido ver que aunque trae problemas entre ellos y con nosotros ¡bueno $;$ nos sale a cuenta...hace dos años estuvimos pensando en cerrar el tema...pero bueno, lo mantenemos por otros motivos...se sienten mejor si te dicen lo que saben..." (Empresa 3 ).

“...Desde hace años que nos interesa saber qué dicen los operarios cuando les vamos a cambiar la máquina o el equipo de medición...Ellos, ya sabes, llevan años aquí...conocen de largo lo que funciona o no...Pero la "pela" la pone la empresa y por lógica es la que decide lo que más interesa...No hay problema, luego ya te dicen qué has de arreglar o cambiar...es lógico siempre tienes algo que no va o que no se adapta bien con lo que necesitas...les llamo [al suministrador] y mañana ya está arreglado o me cambian el aparato si hace falta..." (Empresa 4).

“...Cuando se compran nuevos robots, se consulta a veces a los trabajadores, pues tienen mucha experiencia en esa materia...Su participación consiste, además de trabajar "fino", en sacar esa experiencia "a flote" y "darle a la cabeza" para mirar qué mejora se le puede añadir cuando ya los tenemos en nuestro taller, para que la adaptación que se tenga que hacer sea rápida y eficiente cuando los tengamos que meter en casa de nuestro cliente..." (Empresa 10).

Es decir, a pesar de que en este grupo de empresas los "representantes" fueron consultados por sus respectivas direcciones para conocer sus intenciones 
u opiniones a cerca de la introducción de la principal tecnología, no por ello la extensión de la participación fue más allá de las actuaciones a posteriori, tras haberse implantado la "principal" tecnología. Y eso, incluso en la empresa 3, en la que, como ya se ha comentado, las atribuciones se ampliaron también a la fase de Evaluación:

“...Ya te he dicho antes que siempre les consultamos, incluso antes de cambiar una máquina por otra...Les dejamos que nos propongan cosas que no han ido bien de la antigua, pero nosotros valoramos si conviene a la empresa.. Si son muy costosas lo intentamos aplazar para más adelante, para ver si han bajado de precio..." (Empresa 3).

En este último sentido, a pesar de que la participación en la fase de Evaluación de la tecnología habida en esta empresa presuponía un cierto avance cualitativo -en comparación con lo sucedido en las otras dos empresas del grupo al que pertenecía esta empresa - no por ello esa mayor extensión en la participación dejaba de tener carácter correctivo - $\mathrm{y}$, en buena medida, instrumental, como en el caso de todas las anteriores empresas con prácticas de participación-, puesto que se llevaba a cabo, igualmente, una vez que la tecnología había operado a pleno funcionamiento, sin que los respectivos "representantes" hubieran podido incidir en su diseño y, menos aún, en su adquisición.

La participación en la evaluación de las tecnologías constituye un avance cualitativo porque, a diferencia de la participación en la implantación, los trabajadores no sólo han de estar capacitados para detectar y diagnosticar los problemas técnicos que aparecen durante el funcionamiento de las tecnologías (averías, mantenimiento, productividad, ergonomía, seguridad, etc.), y para proponer mejoras o soluciones a esas tecnologías, sino que han de ser también competentes para integrar y analizar toda esa información a fin de ofrecer propuestas de cara a potenciales compras de nuevas tecnologías en el futuro. Todo ello exige que, entre otras cosas, se hayan de tener en cuenta no sólo los costes que pueda suponer la integración de esas nuevas tecnologías, sino también su compatibilización técnica con el resto de las tecnologías que ya existen en la empresa.

Por lo que se refiere a las argumentaciones ofrecidas por los directivos de las empresas 2 y 14 para justificar la participación de los representantes en grado de "Consulta bidireccional" asociado, a su vez, a una extensión que alcanzaba a la fase de Diseño de la principal tecnología, las argumentaciones fueron las siguientes:

“...Los trabajadores participan en tanto que la compra de las nuevas máquinas estrusoras se decidió por un equipo formado por técnicos, ingenieros, MI y por el propio Comité que discutió la viabilidad....Ahí los trabajadores aportaron sus sugerencias, aunque algunas no las pudimos incorporar por su coste...Algunas que sí aceptamos 
se relacionaban con la autonomía, la cualificación y con la ergonomía, aunque eso no fue negociado con los suministradores... Lo aplicamos aquí, en la medida que las máquinas dejaban un cierto "margen" una vez las compramos...Queremos engrandecer la realización de la persona, porque creemos en el ser humano como la base de la empresa...". (Empresa 2)

“...Se consulta al Comité para resolver conjuntamente problemas en máquinas y para proponer cambios en las ya existentes...En la valoración de riesgos el Comité propone mejoras ergonómicas y de seguridad, sobre todo en máquinas antiguas...Pero aún tenemos dificultades con los ingenieros que aún les cuesta tener en cuenta esto...Como la comunicación es más directa [que con los suministradores externos], casi siempre acaban consiguiendo lo que proponen...tienen fuerza de presión cuando quieren...No participan en las [tecnologías] que compramos fuera porque [el Comité] es demasiado "joven" [está constituido hace unos meses], pero si se pueden aceptar sus propuestas, participarán en el diseño de las máquinas que entren de fuera también...”. (Empresa 14).

A pesar de que la participación no adquirió sus máximas potencialidades en estas dos empresas, el acceso más o menos limitado de los "representantes" al proceso de selección del diseño de la principal tecnología se convertía en un suceso relevante, pues demostraba que en algunas empresas - pocas - el enfoque de la participación en la tecnología podía ser susceptible de superar la dimensión estrictamente instrumental, al constatarse la existencia de una voluntad por ambas partes de alcanzar estadios participativos, cualitativamente superiores.

Es importante destacar que, para lograr este tipo de resultados, no sólo se requiere de la presencia de un estilo directivo más flexible y abierto a la colaboración con la parte social, sino que, aun mostrándose como una condición previa determinante, no siempre resulta ser suficiente si, a su vez, no hay también una voluntad expresa de esa parte social para llegar a esos resultados, es decir, que ese mayor nivel de participación constituya un objetivo explícito del catálogo de reivindicaciones perseguidas por los trabajadores o por sus representantes. Por el contrario, que sea la parte social la que muestre su predisposición favorable hacia ese tipo de participación superior no suele ser condición necesaria para determinar el alcance de tales resultados, puesto que el estatuto jurídico-social que rige el sistema de relaciones laborales vigente ampara a la parte empresarial para decidir, unilateralmente, si acepta o no las aspiraciones presentadas a iniciativa de la otra parte.

Por último, fue en la empresa 7 donde el grado y la extensión de la participación lograron sus niveles más elevados. En esta empresa, la participación tecnológica detectada alcanzó no sólo el máximo grado previsto por esta investigación (grado de Co-decisión), sino que se extendió a todas las fases del proceso de innovación tecnológica, aunque con ciertas limitaciones en la fase de Decisión, en función del volumen de la inversión que exigiera la compra de la tecnología. 
“...En la tecnología yo sólo lo veo al final cuando "los que más saben" deciden que se puede comprar... Y en ese proceso está siempre el delegado de personal, con derecho a vetar la decisión del departamento de Ingeniería, si considera [demostrándolo], que la máquina puede perjudicar a las personas...Tanto es así que la máquina resinadora nos ha costado casi el doble por tenerla que hacer "a la carta"...Tuve siempre claro que aunque fuera más cara, la máquina ha de estar al servicio de las personas y de sus especificidades y no al revés..."

"...Conocemos la filosofia del antropocentrismo/tecnocentrismo, pero hemos tenido problemas, ya te lo he comentado, para encontrar máquinas antropocéntricas en el mercado...Hace años que antes de saber que se llamaba antropocentrismo, ya buscábamos tecnología que concuerda bastante con esto..." (Empresa 7)

Un tipo de razonamientos como los anteriores difícilmente son posibles si, como ya se ha dicho para las dos empresas precedentes, no existe un contexto sociocultural favorable al compromiso subjetivo y a la confianza mutua entre la dirección y los "representantes", en tanto que punto de partida para hacer que -y esta es la diferencia con los dos casos anteriores - la negociación se desarrolle entre ambas partes en términos de equidad de poder, convirtiéndose en la forma sistemática de tomar las principales decisiones en la empresa.

“...Quiero que todos tomen el máximo de responsabilidades y sean totalmente autónomos. La responsable de compras sólo me explica al cabo del tiempo qué hemos comprado, a qué precio y a quién, y son muchos millones. Si me llaman a mí, les digo que hablen con ella. Esto lo hacía yo. Ahora ella tiene total autonomía y si se equivoca (ya pasó), yo asumo el error como mío, nunca la desacredito..."

“...Nunca ha habido grandes conflictos, sólo problemas a solventar como en todas las empresas. Aquí se saluda a todo el mundo empezando por mí cada día. Nunca se ha despedido a nadie y la reducción de trabajo por la automatización se ha compensado siempre ubicando a las personas afectadas en otros puestos de trabajo..Estoy contento de dejar abierto mi despacho. No hay jerarquías ni historias. No quiero perder este "espíritu". Cuando me voy de viaje, nunca llamo para saber si han venido a trabajar todos, si trabajan o no. Estoy totalmente confiado en mi personal..."

“...Cuando en 1993 tuvimos una crisis, los reuní a todos y les dije: el primero en no cobrar, voy a ser yo, dejé de cobrar durante 5 meses y les di la cuenta corriente con autorización para poder ir al banco y verla. Sólo les pedí que en tres meses pidieran el subsidio y con compromiso de readmitirlos de nuevo y así fue.." (Empresa 7)

Sólo bajo un sustrato ideológico-cultural como el expuesto por este directivo es posible que, cuando los trabajadores o sus representantes sindicales tienen la 


\section{R I S}

voluntad explícita de alcanzar mayores cuotas de participación en la tecnología, pueda iniciarse el desarrollo de un proceso de participación integral que, si bien presupone para la dirección la cesión de un conjunto importante de prerrogativas para poder ser co-decididas con la parte social, también asegura que, sólo mediante ese procedimiento, los trabajadores acepten, voluntariamente, los grados de co-responsabilidad correspondientes derivados de esa mayor participación en la empresa.

\section{Tipología organizacional de las empresas estudiadas}

Tras ver las expresiones aducidas por los directivos para justificar los niveles de participación obtenidos en la principal tecnología en las quince empresas estudiadas, se pasó a hacer corresponder esos niveles con una determinada tipología organizacional, en función de cuál había sido el alcance de dichos niveles eñ cada una de dichas empresas.

Para ello, se definieron cuatro "tipos ideales" de modelos de gestión empresarial - convenientemente justificados en la investigación - a partir de recoger el espectro de los principales rasgos identitarios que caracterizan y distinguen a esos modelos, en cuanto a su mayor o menor propensión en favor de la participación en general y, particularmente, en la tecnología.

Finalmente, se pasó a comparar esos cuatro modelos de gestión - "Taylorista", "gerencialista", "humanista-paternalista" y "democrático"- con otros tantos tipos de control sobre la principal tecnología - "nulo", mínimo", "medio" y "elevado"deducidos, a su vez, de los niveles de participación efectivamente alcanzados.

\section{Cuadro 5.}

Tipología organizacional de las empresas estudiadas, según la participación alcanzada por los "representantes" en la principal tecnología.

\begin{tabular}{|l|c|c|c|c|}
\hline & $\begin{array}{c}\text { Empresas } \\
\text { "Tayloristas" }\end{array}$ & $\begin{array}{c}\text { Empresas } \\
\text { Gerencialistas" }\end{array}$ & $\begin{array}{c}\text { Empresas } \\
\text { "Humanistas- } \\
\text { Paternalistas" }\end{array}$ & $\begin{array}{c}\text { Empresa } \\
\text { Democráticas" }\end{array}$ \\
\hline EMPRESAS & Empresas & $\begin{array}{c}\text { Empresas } \\
1,11,12\end{array}$ & $\begin{array}{c}\text { Empresas } \\
2,14\end{array}$ & $\begin{array}{c}\text { Empresa } \\
7\end{array}$ \\
\hline $\begin{array}{l}\text { Control de los } \\
\text { "representantes" } \\
\text { sobre la tecnología }\end{array}$ & NULO & MÍNIMO & MEDIO & ELEVADO \\
\hline
\end{tabular}

Fuente: Elaboración propia. 
De la información contenida en el anterior cuadro 5, pudo deducirse lo siguiente:

- Las empresas 5, 6, 8, 9, 13 y 15 respondieron con claridad a un modelo organizativo de carácter "taylorista", asociado a un tipo de control para los representantes sobre la principal tecnología de índole "nulo", puesto que no se pudo detectar participación alguna, ni en grado ni en extensión. Y eso es así porque el modelo taylorista se caracteriza por concebir la tecnología como el mejor instrumento para incrementar la productividad del trabajo mediante la automatización sucesiva de los procesos de trabajo, con el objetivo último de sustituir, progresivamente, el trabajo por capital. Bajo esa lógica, la participación de los trabajadores no sólo no tiene cabida porque la dirección se niega a admitir cualquier tipo de aportación o propuesta de los primeros, sino porque, en el caso de ser aceptadas, lo que pueden conseguir es que se acelere aún más su sustitución al incrementar la eficiencia de la tecnología con sus propuestas de mejora.

- Las empresas 1,11 y 12 respondieron a un modelo organizativo debilmente "gerencialista" pues, a pesar de que se pudo detectar ciertas prácticas participativas en la fase de Implantación de la principal tecnología, todas ellas lo fueron a iniciativa de la propia empresa, aunque con ausencia total de información e interacción entre las dos partes, coincidiendo en esto último con el modelo "taylorista". Se trataba pues, de empresas híbridas, localizadas en la frontera entre el taylorismo y el gerencialismo, en las que sólo se promueve la participación de los trabajadores para alcanzar con más rapidez y menos resistencias de éstos los objetivos de la empresa.

- Las empresas 3, 4 y 10 respondieron a un modelo de gestión, típicamente "gerencialista", en la medida en que el nexo que existía entre el grado (Consulta unidireccional) y la extensión (fase de Implantación) se correspondía, coherentemente, con una concepción de la participación distinta a la del modelo taylorista, al no considerarse objetivo prioritario la sustitución del trabajo por la tecnología porque la implicación de los trabajadores en la gestión del trabajo es percibida aquí como algo que puede ofrecer unos resultados para la empresa que podrían superar a los que se consiguen con el modelo taylorista. Aun así y, a pesar de las diferencias entre ambas situaciones, se trataba de dos versiones de un mismo modelo, por lo que el control —en este caso mínimo - sobre la tecnología que se derivaba para los "representantes" de la tecnología era parecido en las dos situaciones.

- Las empresas 2 y 14 respondieron, por su parte, a un modelo organizativo de tipo "humanista-paternalista", asociado a un tipo de control del nivel medio sobre la principal tecnología. A pesar de que estas empresas compartían con las gerencialistas la prioridad productivista (como fin último de la participación en la tecnología), la mayor participación alcanzada (al incluir, no sólo las fases de Implantación y Evaluación, sino también, aunque con ciertos límites, la fase 
R I S

crítica del Diseño de la principal tecnología) confirmaba la existencia de un estilo directivo que, sin ser plenamente democrático, se distinguía de los anteriores por apostar por un clima de trabajo y unas relaciones sociales propicias a una mayor proximidad y confianza. Esta apuesta se planteaba como premisa para crear en los trabajadores las condiciones de una implicación subjetiva superior $\mathrm{y}$, con ello, conseguir con mayor consenso y legitimidad los objetivos de la empresa, distanciándose así del utilitarismo e inmediatez economicista con que el gerencialismo se plantea la participación. Ahora bien, a pesar de todo ello, ni esas relaciones sociales suelen ser ajenas a un cierto paternalismo, ni los beneficios de la "proximidad" son enteramente simétricos, puesto que la dirección de este tipo de empresas siempre se reserva para sí espacios exclusivos de poder sobre los que siempre tiene la última palabra (como a la hora de decidir el diseño definitivo de la tecnología y, por supuesto, la compra y los objetivos que se quieren conseguir con ésta).

- Finalmente, la empresa 7 fue la única que se aproximó a una tipología de organización "democrática". A pesar de que no respondió íntegramente al caso óptimo definido en esta investigación (máximo grado y participación en todas las fases del proceso de innovación tecnológica), esa aproximación fue muy alta, por lo que el tipo de control para los representantes sobre la "principal" tecnología resultó ser de índole elevada. $\mathrm{Y}$ eso fue posible gracias a la existencia de una predisposición de la dirección para alcanzar acuerdos consensuados y sólidos con la parte social sobre la gestión de la organización del cambio tecnológico y de las consecuencias que se pudieran derivar para el propio trabajo. En realidad, el modelo de gestión "democrática" se caracteriza, a diferencia de lo que sucede con los modelos anteriores, por concebir a la tecnología como un objetivo en sí mismo y no sólo como un medio. En este modelo, la búsqueda de la máxima productividad de la tecnología se intenta compatibilizar con las necesidades personales y sociolaborales que tienen los trabajadores, siendo la tecnología un instrumento que ha de facilitar esas necesidades, intentando que el trabajo se convierta en una experiencia cualificante y satisfactoria para aquellos. En este tipo de empresas, las relaciones de mutua confianza no sólo no quedan al criterio más o menos arbitrario de la voluntad de los directivos, como en el caso anterior, sino que están formalizadas en normas equitativas para que la toma de las decisiones importantes se realice, conjuntamente, por consenso entre las dos partes. En un contexto como éste, la participación en la gestión del proceso de innovación tecnológica no sólo propicia el alcance del máximo grado y extensión, sino que puede dar paso a la co-determinación de otro tipo de decisiones de nivel superior (como la definición de los objetivos de la empresa) si así lo acuerdan las dos partes y sin que ninguna de ellas pueda imponer sus criterios sobre la otra. 


\section{CONCLUSIONES}

A la vista de los resultados obtenidos, pueden apuntarse una serie de comentarios y reflexiones, siempre teniendo presente que su validez sólo puede serlo para las empresas estudiadas. No obstante, con la debida precaución metodológica a que obliga el uso de técnicas cualitativas de investigación, pueden ser extrapoladas a otras empresas del citado sector auxiliar y de otros sectores de actividad que compartan características similares con las empresas aquí estudiadas.

- En primer lugar, los resultados obtenidos en las empresas estudiadas en esta investigación informan de la presencia de un destacado grado de exclusión estructurada de los "representantes" de la participación en la tecnología. Y eso es así porque, cuando la participación ha existido, lo ha hecho con un grado o intensidad escaso, y sólo cuando las tecnologías estaban ya funcionando. En otras palabras, en la mayoría de las empresas estudiadas, o no había participación o, si existía, se limitaba a las fases más operativas y menos comprometidas para los directivos de esas empresas.

La persistencia de una política de exclusión de la participación, incluso cuando la dirección aporta información, pero es insuficiente o/y y tardía (Larrea, 1994: 134), puede ser interpretados por los trabajadores y sus representantes como un motivo de esa dirección para ocultarles decisiones que pueden ir en contra de sus intereses (Aragón, 1998: 125). Podría dar lugar también, como contrapartida no deseada por algunos directivos, a que los trabajadores se desvinculen de cualquier corresponsabilidad para con los cambios y problemas que se suelen derivar cuando se introduce la tecnología sin su concurrencia.

No obstante, este tipo de resultados no se aparta demasiado de las grandes tendencias ya detectadas en los países europeos a finales de los años ochenta (Cressey, 1990: 106). Estas tendencias confirmaban que, salvo en los países escandinavos y algunos casos excepcionales de toma de decisiones conjunta en el resto de países, en la mayor parte de las empresas europeas se percibía a la tecnología como un instrumento de potestad exclusiva de la dirección, siendo ésta la principal responsable de que la participación estuviera concentrada en la fase de Implantación y, por tanto, excluida del resto de fases del proceso de innovación tecnológica. $\mathrm{Si}$ este era el panorama general que existía en Europa a finales de la década de los ochenta y ha coincidido, en términos generales, con los resultados aquí obtenidos podría apuntarse como hipótesis - con las necesarias precauciones metodológicas y la posible influencia de otras variables, aquí no contempladas- que ese diferencial de años (más de una década) podría aproximarse al desfase temporal del retraso en el que se encuentra este tipo de participación en Cataluña respecto de la media europea.

- En segundo lugar, los resultados obtenidos sugieren igualmente que, 
cuanto mayor es el grado de que disponen los "representantes" para participar en la tecnología, mayor es también la amplitud de la participación en el proceso de innovación tecnológica. En otras palabras, y como ejemplo, sólo es posible participar en todas las fases de ese proceso si, previamente, los "representantes" tienen reconocido el poder necesario para co-decidir con la dirección. Lo contrario - poder participar en la tecnología sin tener reconocido ese poder - sólo es posible detectarlo cuando esa participación es de poca entidad, normalmente iniciada a instancias de las propias empresas.

Por tanto, para que los trabajadores o los representantes sindicales puedan participar en las fases que exigen la toma de decisiones técnicamente más complejas y, a su vez, más comprometedoras para los directivos (Lahera, 2001: 112), además de disponer de las habilidades técnicas y sociales necesarias para contraponer sus propuestas a las ofrecidas por la dirección, han de poseer también las atribuciones de poder pertinentes para que la participación en esas fases más críticas se pueda materializar efectivamente.

La supuesta incapacidad técnica de los representantes - a menudo esgrimida por algunos directivos - para poder participar en esas fases responde más a razonamientos ideológicos y a intereses ligados al mantenimiento unilateral de las prerrogativas de poder (Levinson, 1977: 91), que a una verdadera incapacidad de aquellos para tomar ese tipo de decisiones, pues hoy hay los suficientes recursos formativos y de otra índole como para cubrir la supuesta ausencia de cualificación.

No obstante, la posesión del grado de poder necesario para participar se mostró sólo como una condición necesaria, pero no suficiente. A pesar de que en algunas empresas los representantes disponen de un cierto grado para participar - por ejemplo, el de "consulta unidireccional" en la empresa 10- mayor que el que disponen los representantes de las empresas tayloristas, no por ello los resultados en la extensión de dicha participación alcanzan niveles superiores en esas empresas, pues, como se pudo comprobar, además de disponer de un mínimo grado de poder, los trabajadores y sus representantes también han de "querer" aprovechar ese poder; y esa relación no siempre es directa, ya que para ello se require la identificación con unas ciertas ideas y valores.

- En tercer lugar, la ausencia de participación de los representantes de las empresas "gerencialistas" en la fase de Evaluación - salvo en la empresa 3-viene a confirmar que, aun siendo un tipo de participación menos crítica para los directivos que la que tiene lugar en las fases más estratégicas, tal participación sigue quedando, mayoritariamente, descartada como objetivo. Algo ya constatado en otros países de nuestro entorno a principios de los noventa (Smits, 1993: 21).

Con este tipo de resultados, es fácil deducir que la importancia que los directivos y empresarios conceden al diagnóstico evaluativo de los problemas que genera la explotación de las tecnologías conjuntamente con los trabajadores 
o con sus representantes, sigue siendo muy escasa. De esa forma se pierde la oportunidad para aprovechar el bagaje de aprendizajes y experiencias que estos últimos acumulan durante el uso y la conducción de las tecnologías - en tanto que cualificación susceptible de beneficiar a ambas partes - para acordar las nuevas prestaciones y características que habrán de tener las futuras tecnologías, una vez vistos los problemas y ventajas de las anteriores.

- En cuarto lugar, es posible intuir que los resultados detectados en esta investigación pueden mostrar un cierto avance experimentado a lo largo de los últimos años. ${ }^{5}$ es que algunas empresas aquí catalogadas como "gerencialistas" podrían haber evolucionado desde un taylorismo "puro" inicial, hacia otras formas de gestión más participativas (bien por propia voluntad planificada, bien por adaptación pragmática a los cambios impuestos por el entorno) (Regini, 1992: 62), o incluso hacia otras formas de participación todavîa más comprometidas que las "gerencialistas". Por ello, no es posible concluir con rotundidad que la participación tecnológica no haya sufrido avance alguno, desde que se inició el proceso de innovación tecnológica a mediados de la década de los ochenta, a pesar de los escasos resultados que se han detectado.

Sin embargo, aun admitiendo que se hubiese podido producir tal avance, lo que sí parece haber sucedido es que no ha existido una institucionalización definitiva de las prácticas participativas, dado el carácter informal, inestable y específico con que se han establecido esos posibles avances en cada empresa. En este sentido, la precariedad de bastantes de los logros que se han podido conseguir en la participación en el cambio tecnológico de algunas de las empresas aquí estudiadas, podría conllevar a que algunos directivos se desdijeran y revocaran sus compromisos sin demasiados problemas.

La aparición de cualquier coyuntura de orden político, económico-financiero o institucional que pudiera comprometer el logro de unos determinados objetivos económicos, podría convertirse en un desafio a la participación tecnológica alcanzada en algunas empresas porque, igual que se implantó en su momento como instrumento para afianzar una mayor productividad, se puede suprimir en cualquier otro si los beneficios de productividad que aquélla proporciona dejan de compensar los costes que genera.

\footnotetext{
${ }^{5}$ Se trata de una intuición porque es algo, prácticamente, imposible de saber, si se tiene en cuenta que, como ya se ha indicado, no se ha publicado - al menos hasta el momento en el que se realizaba esta investigación - ningún estudio empírico sobre este tema específico con el cual poder establecer algún tipo de comparación, y menos aún, con una metodología parecida o equiparable a la que aquí se siguió, y que se haya desarrollado en el territorio español y, mucho menos aún, en el de Cataluña, que no sea el ya comentado de la Fundación Europea para la Calidad de Vida y del Trabajo, realizado para diversos países europeos, a finales de la década de los ochenta.
} 
Este podría ser, por ejemplo, el caso de algunas de las empresas catalogadas en esta investigación de "gerencialistas" (empresas 3, 4, 10,11 y 12), puesto que la participación tecnológica que se desarrolla es meramente instrumental y de carácter informal, sin que existiera acuerdo alguno con los representantes sindicales para formalizar esa participación de forma duradera, al menos allí donde esa representación existía (sólo en las empresas 10 y 11).

- En quinto y último lugar, e insistiendo en la ausencia de datos empíricos comparables con este tipo de participación, el único estudio con el que se pudo establecer una mínima comparación de los resultados fue, con el realizado por la citada Fundación Europea para la Mejora de las Condiciones de Vida y de Trabajo para los doce países que formaban la Unión Europea a finales de los ochenta, incluida España.

Aunque las técnicas de investigación y los criterios utilizados para clasificar la información por ese estudio no coincidían exactamente con los utilizados por esta investigación (Fröhlich et al.; 1990, 5-7), el aspecto específico de la participación en la tecnología que exploró dicha Fundación (grado de "Co-decisión), permite ofrecer el cuadro 7 comparativo. Este Cuadro 7 muestra los resultados de la participación tecnológica alcanzados por las dos investigaciones en el momento de realizar los respectivos trabajos de campo.

Así, la comparación entre el porcentaje que alcanzaba la participación en la tecnología en España (5\%) y la media de la UE (10\%) en el estudio de la FEMCVT, pone de manifiesto el menor desarrollo que había en España de ese grado de participación en la fase de Decisión (concretamente, un 50\% menor).

De otro lado, la comparación con los resultados obtenidos por esta investigación - para ese mismo grado de participación — con los de la citada Fundación

Cuadro 7.

Comparación de los resultados de la participación en la fase de Planificación/Decisión por \% de empresas.

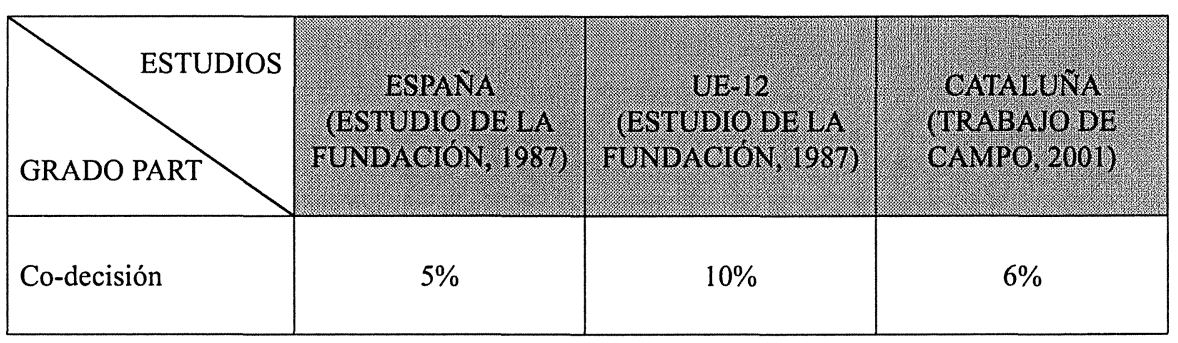

Fuente: Elaboración propia, a partir de datos de la FEMCVT. 
para España y para la UE, permite comprobar que, trascurridos catorce años, tan sólo en un 6\% de las empresas estudiadas en Cataluña (es decir, en una sobre un total de quince), los representantes habían alcanzado los máximos niveles de participación posibles en empresas que operan en el mercado capitalista. Por ello, a pesar del hipotético avance que pudiera haberse experimentado en la participación tecnológica durante los últimos años, no parece - al menos en aquélla que conduce a la necesidad de un mayor compromiso de las dos partes- que haya progresado suficientemente como para acercarse a los niveles con los que se desarrolla este tipo de participación en el resto de Europa.

\section{REFERENCIAS BIBLIOGRÁFICAS}

ARAGÓN SÁNCHEZ, A. (1998), La participación de los empleados en la empresa, Madrid, Consejo Económico y Social.

BAMBER, G. (1993), “Cambio tecnológico y sindicatos”, en R. Imán y W. Steeck (comp..), Nuevas tecnologias y relaciones industriales, Madrid, Ministerio de Trabajo y Seguridad Social.

CORNFIELD, D.B. (1995), "Potencial participativo de las nuevas tecnologías”, Sociologia, nº 23.

CRESSEY, P. (1990), "Nuevas tecnologías y participación de los trabajadores", Sociologia del Trabajo, $\mathrm{n}^{\circ} 9$.

FERNÁNDEZ STEINKO, A. (1997), Continuidad y ruptura en la modernización industrial de España, Madrid, Consejo Económico y Social.

FREYSSENET, M. (1995), "La production reflexive, une alternative à la production de masse et à la production au plus juste?”, Revista Sociologie du Travail, tercer trimestre, París.

FRÖHLICH et al. (1990-1991), "Caminos hacia la participación en la Comunidad Europea”, Revista Sociología del Trabajo, $\mathrm{n}^{\circ} 11$.

FUNDACIÓN EUROPEA PARA LA MEJORA DE LAS CONDICIONES DE VIDA Y DE TRABAJO (1991), Análisis de la participación: un balance de los estudios de la Fundación en materia de participación de los trabajadores en las decisiones de las empresas, Dublín, Irlanda.

FUNDACIÓN EUROPEA PARA LA MEJORA DE LAS CONDICIONES DE VIDA Y DE TRABAJO (EPOC) (1996), Acortar distancias: la participación directa en el cambio organizativo, Luxemburgo.

JUAN, J. (2001), "Las restricciones a la participación de los trabajadores en las organizaciones empresariales", Papers, $\mathrm{n}^{\circ} 65$.

LAHERA, A. (2001), La participación de los trabajadores en la empresa: ¿Hacia la democratización de las relaciones indutriales? Una propuesta metodológica de análisis, en A. Fernández 
Steinko y D. Lacalle, Sobre la democracia económica. La democracia en la empresa, Barcelona, Ed. Viejo Topo.

LARREA GAYARRE, J. (1994), "Innovación técnica o nuevas tecnologías", Cuadernos de Sección: Sociedad, Técnica y Tecnología, $\mathrm{n}^{\circ} 1$.

LEVINSON, C. (1977), La democracia industrial, Madrid, Ed. Asociación para el Progreso de la Dirección.

O.C.D.E. (1993), Gestión de Recursos Humanos y Tecnologias de fabricación avanzada, Madrid, Ministerio de Trabajo y Seguridad Social.

O.I.T. (1987), La participación en la empresa 1981-1985, Madrid, Ministerio de Trabajo y Seguridad Social.

SMITS, R. (1993), "Situación actual de la evaluación de tecnología en Europa", Quaderns de Tecnología, $\mathrm{n}^{\circ} 7$, Institut Catalá de Tecnología, Barcelona. 